\title{
Optoelectronic Detection of Disease Biomarkers in Air Exhaled from Human Lungs
}

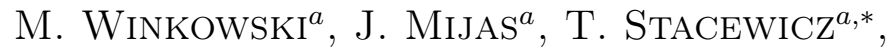 \\ Z. BIELECKI ${ }^{b}$ AND J. WOJTAS ${ }^{b}$ \\ ${ }^{a}$ Institute of Experimental Physics, Faculty of Physics, University of Warsaw, \\ L. Pasteura 5, O2-094 Warsaw, Poland \\ ${ }^{b}$ Institute of Optoelectronics, Military University of Technology, \\ S. Kaliskiego 2, 00-908 Warsaw, Poland \\ Doi: 10.12693/APhysPolA.139.231 \\ *e-mail: tadeusz.stacewicz@fuw.edu.pl
}

\begin{abstract}
Biomarkers are compounds whose excessive concentration in breath may indicate disease states. High precision laser absorption techniques, such as the multipass spectroscopy and cavity ring down spectroscopy at wavelengths corresponding to strong absorption lines of these compounds, are the appropriate methods for a sensitive detection of biomarkers in breath. In this paper, we present our achievements in optical detection of $\mathrm{CH}_{2} \mathrm{O}, \mathrm{C}_{2} \mathrm{H}_{6}, \mathrm{NO}_{2}, \mathrm{OCS}, \mathrm{NH}_{3}, \mathrm{CH}_{4}$, and $\mathrm{CO}$. The presented results prove that with such systems, the detection of pathogenic changes at the molecular level is possible.
\end{abstract}

topics: disease biomarker, laser spectroscopy

\section{Introduction}

Numerous trace compounds present in human breath contain information about individual features of the body, as well as on the state of a person's health [1-3]. An excess of some of these compounds (called biomarkers) can be related to certain diseases. Therefore, the investigation of air exhaled from human lungs can serve as an effective tool of identifying various sicknesses at an early stage of their development. For that reason, a search for novel methods of biomarkers determination is desirable $[4,5]$. A novel type of breath analyzers, which can be developed owing to progress in laser spectroscopy and optoelectronics, can be cheap, selective, sensitive and simple in maintenance. Their non-invasiveness and real time measurement $\approx 1 \mathrm{~min}$ are their main advantages when compared to the existing medical diagnostic procedures.

The main goal of our work is to develop optoelectronic sensors of various biomarkers in human breath.

\section{Experimental}

An optical approach to biomarker detection in air is based on the measurement of light absorption in a gas sample at a wavelength that is specific for a compound of interest (the so-called fingerprint). The main difficulty is that this absorption is weak, since the concentration of the majority of biomarkers is much lower than $1 \mathrm{ppm}$. Therefore, high selectivity and sensitivity of the detection system is required.

\subsection{Absorption spectrum selection}

More than 3,000 various compounds were already detected in exhaled air [4]. The mid-wavelength infrared (MWIR) range is the best range for optical detection because for many species the lines are strong and well distinguishable. Nevertheless, one has to avoid a spectrum disturbance by the absorption bands of other gases (the so-called interferents) which are present in human breath. We will show the method of the fingerprint and the experimental circumstances selection on examples of formaldehyde and ethane - the biomarkers of cancer and other diseases $[1,6]$.

The formaldehyde absorption spectrum in the MWIR range consists of two main bands situated close to 3.6 and $5.8 \mu \mathrm{m}$ [7]. The $5.8 \mu \mathrm{m}$ band is strongly affected by $\mathrm{H}_{2} \mathrm{O}$ absorption whose concentration in breath exceeds formaldehyde density by many orders of magnitude. The $3.6 \mu \mathrm{m}$ band is weaker but can be more easily used for the optical detection of this compound due to cheaper photodetectors and optical materials $[8,9]$. It is, however, still interfered by a strong absorption of $\mathrm{H}_{2} \mathrm{O}, \mathrm{CO}_{2}$ (both up to $\approx 5 \%$ in breath) and $\mathrm{CH}_{4}$ (up to $5 \mathrm{ppm}$ ), as shown in Fig. 1a. The separation of spectra of these compounds might be achieved by lowering of the gas pressure in the 


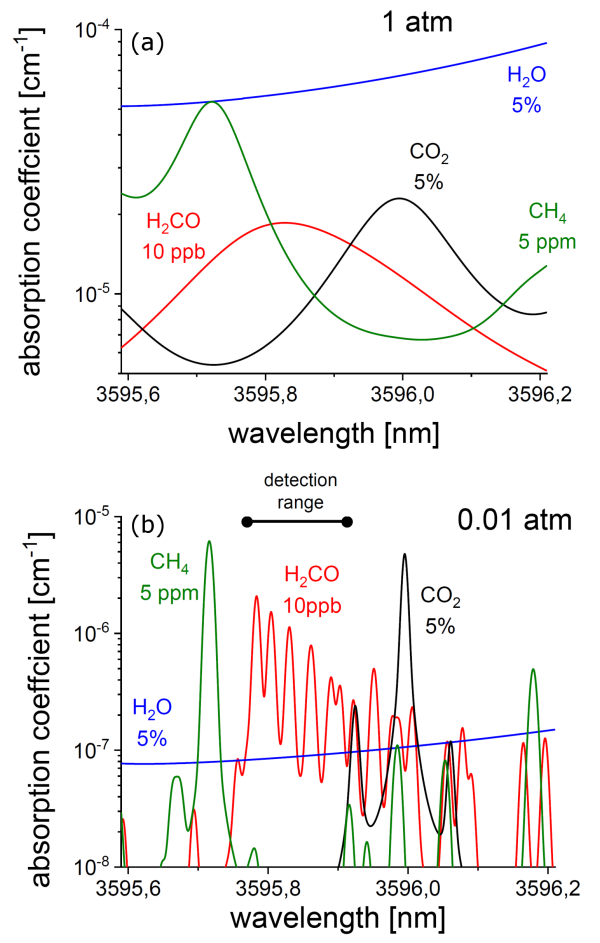

Fig. 1. Absorption spectra of formaldehyde at the pressure of $1 \mathrm{~atm}$ (a) and $0.01 \mathrm{~atm}(\mathrm{~b})$ together with the spectra of the main interferents present in breath.

sample to the value of 0.01 atm (see Fig. 1b). It causes a decrease of collisional line broadening [10]. As a consequence, the overlap of lines is reduced. Due to that, a sensitive optical detection of $\mathrm{CH}_{2} \mathrm{O}$ can be performed within the wavelength range of $3595.77-3595.91 \mathrm{~nm}$. Although this is not the strongest line set in the $3.6 \mu \mathrm{m}$ band, we found that it is the least disturbed by the interferents, and consequently, it is the best fingerprint for the detection of trace amounts of this biomarker in breath.

The ethane absorption band is located near $3337 \mathrm{~nm}$ and consists of nine spectral lines [11]. In the gas mixture exhaled from the lungs, this band can be disturbed by $\mathrm{H}_{2} \mathrm{O}, \mathrm{CH}_{4}$ and $\mathrm{CH}_{2} \mathrm{O}$ absorption (see Fig. 2a). The line of the order of $3336.8039 \mathrm{~nm}$ is the best for ethane detection. The pressure lowering to $0.1 \mathrm{~atm}$ is sufficient to separate this line from the interferences (see Fig. 2b).

\subsection{Experimental setup}

A high sensitivity of absorption measurement can be achieved due to the application of special methods. The cavity ring-down spectroscopy (CRDS) [12-14] and the multipass spectroscopy (MUPASS) $[15,16]$ belong to these approaches ${ }^{\dagger}$.

\footnotetext{
†Optoacoustic spectroscopy (especially its quartz enhanced version - QEPAS) also belongs to these approaches. However, it is not applicable to the measurement described in this paper due to necessity of using of the reduced sample pressure
}
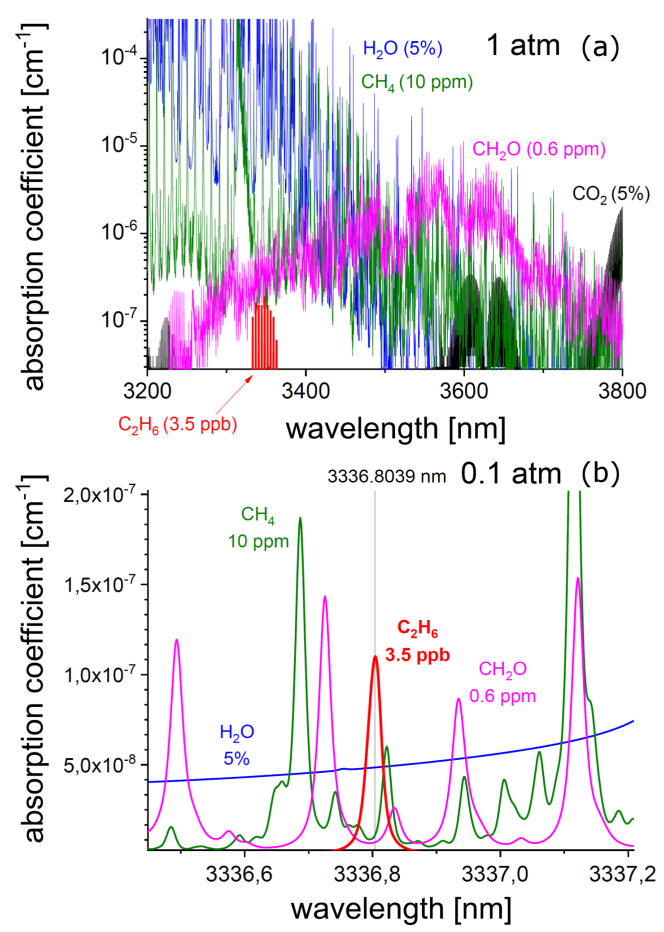

Fig. 2. Description as in Fig. 1, but for ethane.

Our experimental setup for CRDS is shown in Fig. 3a. It was used for nitrogen dioxide, nitric oxide, and carbonyl sulphide detection. The investigated gas sample was placed in an optical cavity whose quality factor was measured by an amplitude modulated semiconductor laser. The laser was tuned to the fingerprint of the compound of interest by temperature and current controllers. Using an oscilloscope, a decay of radiation intensity transmitted through the resonator was observed. This served for the determination of a photon lifetime $\left(\tau_{A}\right)$ in the cavity. The presence of the absorbing compound caused light quenching. As a consequence, a decrease of the $\tau_{A}$ value was observed in respect of the photon lifetime $\left(\tau_{o}\right)$ measured in the cavity free of the absorbing molecules. This enabled to determine the absorber concentration using

$$
N=\frac{1}{\sigma c}\left(\frac{1}{\tau_{0}}-\frac{1}{\tau_{A}}\right),
$$

where $\sigma$ denotes the absorption cross-section and $c$ is the light speed.

The setup for a MUPASS experiment is presented in Fig. 3b. An absorption cell equipped with two mirrors was applied. The laser beam was introduced to the cell through a small hole in one of the mirrors and then multiply reflected between the mirrors. About $20 \mathrm{~m}$ light path was achieved in the sample. Due to that, a much larger sensitivity was achieved than for the single pass spectrometry. The laser wavelength was scanned across the absorption line of the compound of interest using current modulation by the $91 \mathrm{~Hz}$ signal from a 2-channel generator. The absorber concentration was calculated 

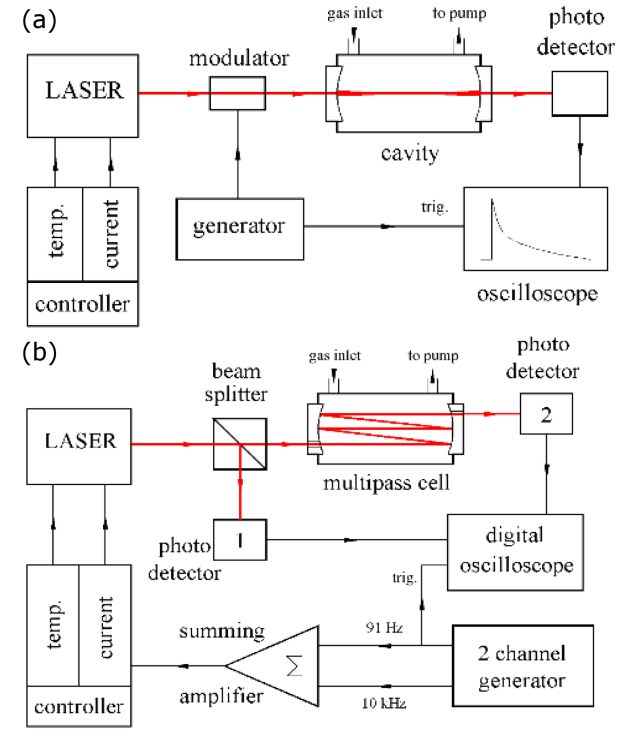

Fig. 3. Simplified experimental setups for (a) CRDS, (b) MUPASS.

using the Lambert-Beer law. Such a solution was applied for ethane, carbon monoxide, methane, ammonia, and formaldehyde detection.

One of spectral disturbances affecting optical systems takes place due to the unexpected interferences between the light beams. In the MUPASS cells it occurs due to the overlapping of the radiation scattered on various optical surfaces or in the gas. This leads to a modulation of the registered spectrum by the periodic fringes. Such a disturbance can significantly spoil the accuracy of the experiment. We found that the wavelength modulation over the fringes period and the signal averaging can effectively reduce these disturbances [17]. From a mathematical point of view, the method is based on the theorem that the averaging of any periodic function over its period (or multiplicity of the period) provides the mean function value that is constant. The $10 \mathrm{kHz}$ sine signal from a 2-channel generator was used for this purpose (see Fig. 3b). It served for an additional laser wavelength scanning. Its amplitude, and consequently the range of wavelength modulation, was adjusted manually, through looking at the oscilloscope for the best minimization of the interferences. The averaging (over 1,000 trigger pulses) was performed with a digital oscilloscope.

\section{Measurement and results}

Using the methods described above, we developed a set of sensors for the detection of several biomarkers of various important diseases. The results are shown in Table I. Beside formaldehyde and ethane, the application of the pressure reduction was also necessary for NO (0.1 atm). The detection of other compounds, i.e., $\mathrm{NO}_{2}, \mathrm{OCS}, \mathrm{NH}_{3}, \mathrm{CH}_{4}$, and $\mathrm{CO}$, was performed at normal pressures.

The approaches to the detection of $\mathrm{NO}, \mathrm{NO}_{2}$, OCS, CO, $\mathrm{CH}_{4}$, and $\mathrm{NH}_{3}$ were already presented in [15]. Here, we will focus on recent achievements related to formaldehyde and ethane measured using the MUPASS method.

\subsection{Formaldehyde}

After the signal acquisition, further data processing was performed with a custom program. First, the background generated by the semiconductor laser power modulation was removed. The excess white noise was reduced with a low-pass digital filter. Due to that, the characteristic spectral lines of formaldehyde were found. The fragment between the first and fourth minimum was separated (the three strongest lines — see Fig. 1b). The data prepared in this way was then numerically integrated.

Biomarkers detected with our laser spectroscopy methods.

TABLE I

\begin{tabular}{|c|c|c|c|c|c|}
\hline Compound & $\begin{array}{c}\text { Morbid } \\
\text { level }[\mathrm{ppb}]\end{array}$ & $\begin{array}{l}\text { Detection } \\
\text { limit }[\mathrm{ppb}]\end{array}$ & $\begin{array}{c}\text { Wavelength } \\
{[\mathrm{nm}]}\end{array}$ & $\begin{array}{l}\text { Detection } \\
\text { method }\end{array}$ & Diseases \\
\hline nitrogen dioxide & - & 1 & 0.41 & CRDS & \\
\hline nitric oxide & 50 & 10 & 5262.2926 & CRDS & $\begin{array}{l}\text { asthma, hypertension, rhinitis, } \\
\text { airway inflammations }\end{array}$ \\
\hline carbonyl sulfide & 10 & 3 & 4877.7716 & CRDS & $\begin{array}{l}\text { cystic fibrosis, liver failure, acute } \\
\text { rejection of transplanted lungs }\end{array}$ \\
\hline ethane & 3.5 & 1 & 3336.8039 & CRDS & $\begin{array}{l}\text { inflammatory, vitamin E deficiency, } \\
\text { oxidative stress, scleroderma, cancer }\end{array}$ \\
\hline carbon monoxide & $10^{4}$ & 500 & 2333.7197 & MUPASS & $\begin{array}{l}\text { hyperbilirubinemia, oxidative stress, } \\
\text { asthma, respiratory infections }\end{array}$ \\
\hline methane & $10^{4}$ & 100 & 2253.6598 & MUPASS & intestinal problems \\
\hline ammonia & 3000 & 1000 & 1527.0409 & MUPASS & $\begin{array}{l}\text { gastrointestinal ulcers due to } \\
\text { Helicobacter pylori }\end{array}$ \\
\hline formaldehyde & 300 & 6 & 3595.78 & MUPASS & lungs and breast cancer \\
\hline
\end{tabular}




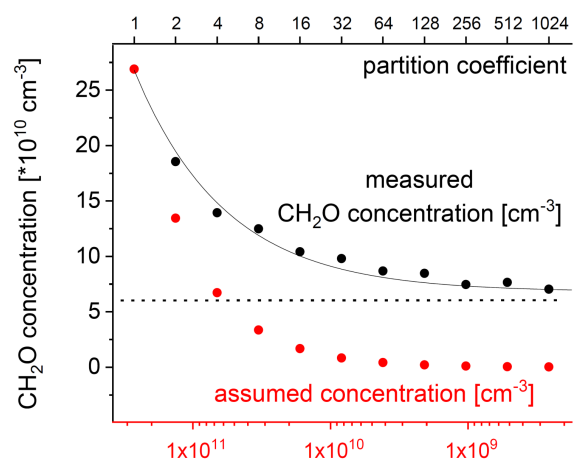

Fig. 4. Results of $\mathrm{CH}_{2} \mathrm{O}$ measurement based on the successive concentration partition.

The results were compared with similar data registered for the 1 ppm calibrated mixture (Linde Gas) that was used as a reference gas.

In order to test the linearity of our sensor for different formaldehyde concentrations, a procedure of a reference mixture dilution in nitrogen was used. In the first step, the mixture at the pressure of $0.01 \mathrm{~atm}$ was set to the sensor. After the signal collecting, the pressure was raised to 0.02 atm using nitrogen. Several minutes later (necessary for the gases intermixing), the pressure was reduced again to the starting value of $0.01 \mathrm{~atm}$. We expected that the mixture with the half density of formaldehyde would be achieved in comparison to the previous one. The consecutive operation of diluting and the signal collecting was repeated ten times.

The results are shown in Fig. 4. It can be observed that a step by step density partition with the coefficient of 2 was not achieved. Only the concentration of about $6 \times 10^{10} \mathrm{~cm}^{-3}$ was achieved in 10 steps, starting from the reference density of about $2.7 \times 10^{11} \mathrm{~cm}^{-3}(1 \mathrm{ppm}$ at $0.01 \mathrm{~atm})$.

A formaldehyde deposit on the system walls was responsible for this effect. This compound adheres to the equipment in the form of a polymer - polyoxymethylene [18]. Once deposed inside the cell at higher $\mathrm{CH}_{2} \mathrm{O}$ concentrations, it later evaporates providing the gaseous formaldehyde.

We decided to benefit from the polyoxymethylene deposition and use it for the detector testing at low formaldehyde concentrations. The cell was evacuated to the residual pressure of $10^{-7}$ atm and then filled with pure nitrogen up to 0.01 atm pressure. Then, due to $\mathrm{CH}_{2} \mathrm{O}$ evaporation from the walls, the sensor was slowly filled with gaseous formaldehyde. The concentration was measured every minute.

Temporal evolution of $\mathrm{CH}_{2} \mathrm{O}$ is presented in Fig. 5. It can be well approximated by an exponential growth

$$
n(t)=A[1-\exp (-k t)]
$$

The optimal values fitted are $k \approx 5 \times 10^{-4} \mathrm{~s}^{-1}$ and $A \approx 6 \times 10^{10} \mathrm{~cm}^{-3}$. This allows to evaluate that the cell was filled to the concentration of about $1.8 \times 10^{9} \mathrm{~cm}^{-3}$ within the first minute of the

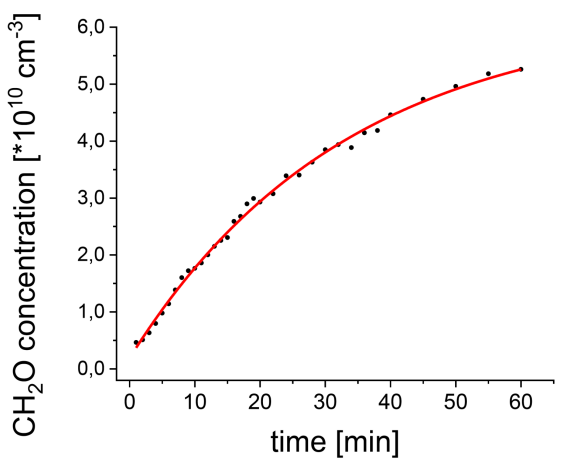

Fig. 5. Changes of $\mathrm{CH}_{2} \mathrm{O}$ concentration due to polyoxymethylene evaporation from walls.

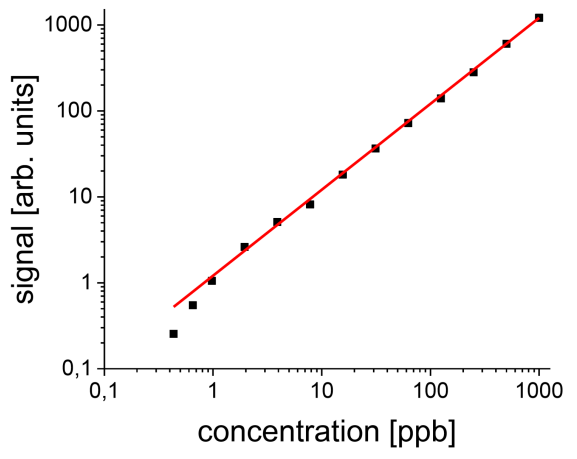

Fig. 6. Test of ethane sensor linearity.

measurement. That corresponds to about $6.6 \mathrm{ppb}$ at $0.01 \mathrm{~atm}$. This is a minimal value of the concentration which can be generated in our experiment. Such a precision shows that our formaldehyde sensor is useful for medical application since the morbid level of formaldehyde in breath was evaluated to be $300 \mathrm{ppb}[19]$.

Formaldehyde evaporation from the apparatus walls makes the measurement of this compound problematic when testing concentrations at the ppb level. We found that an attempt at polyoxymethylene removing by heating (up to $80^{\circ} \mathrm{C}$ ) and pumping is insufficient. Only the Mannich reaction is the approach of the cell decontamination [18]. It requires a temporary filling of the cell by ammonia vapor that reacts with formaldehyde and its polymer. However, the measurement of $\mathrm{CH}_{2} \mathrm{O}$ concentration with clean equipment also causes the results' adulteration due to sticking of the molecules to the walls. This leads to the density lowering within the time scale comparable to that presented in Fig. 5. The reduction of the measurement time to single minutes or less is the method to achieve a sufficient precision, as it was shown in our experiment.

\subsection{Ethane}

In the case of ethane, a facilitation is that $\mathrm{C}_{2} \mathrm{H}_{6}$ does not stick to the walls like formaldehyde. Therefore, the use of the procedure described in Sect. 3.1 in order to test the linearity of the sensor was 


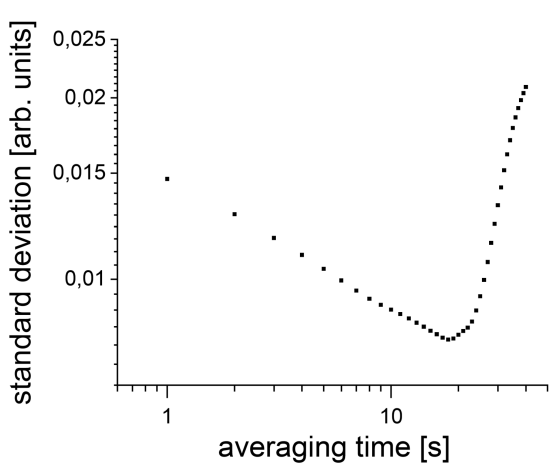

Fig. 7. Allan deviation plot for ethane measurement.

successful. A calibrated 1 ppm ethane cylinder was stepwise diluted in the sensor. According to the spectrum analysis (see Fig. 2b), the experiment was carried out at the pressure of $0.1 \mathrm{~atm}$. The results are shown in Fig. 6. One can evaluate that the sensor worked linearly up to the concentration of $1 \mathrm{ppb}$ (about $2.7 \times 10^{9} \mathrm{~cm}^{-3}$ ).

For this concentration, the Allan deviation plot was performed as well (see Fig. 7) [20]. The optimal precision was achieved for the integration time of $20 \mathrm{~s}$. Its value is $80 \mathrm{ppt}$ approximately. This means that the practically achieved detection threshold of $1 \mathrm{ppb}$ is sufficient for the study of the air exhaled from human lungs since the morbid level of ethane is equal to $3.5 \mathrm{ppb}[18]$.

\section{Conclusion}

We presented optical sensors for the detection of disease biomarkers present in air exhaled from human lungs. The application of ultrasensitive laser absorption methods like CRDS and MUPASS together with various approaches leading to the reduction of interferences (i.e., the separation of spectral lines by pressure lowering or reduction of fringe interferences by the proprietary approach) and special methods of data processing ensured a much better detection limit than the morbid level. That allows to look with optimism for future opportunities of optical breath analysis application in medicine. Continuous progress in optoelectronics will lead to the construction of cheap and easy to maintain desktop systems useful for screening.

\section{Acknowledgments}

This research was supported by the Polish National Science Centre, research project No. 2016/23/B/ST7/03441.

\section{References}

[1] C. Wang, P. Sahay, Sensors 9, 8230 (2009).

[2] J.H. Miller, Y.A. Bakhirkin, T. Ajtai, F.K. Tittel, C.J. Hill, R.Q. Yang, Appl. Phys. B 85, 391 (2006).
[3] A. Ulanowska, T. Ligor, M. Michel, B. Buszewski, Ecol. Chem. Eng. 17, 9 (2010).

[4] B. Buszewski, D. Grzywinski, T. Ligor, T. Stacewicz, Z. Bielecki, J. Wojtas, Bioanalysis 5, 2287 (2013).

[5] J. Rudnicka, M. Walczak, T. Kowalkowski, T. Jezierski, B. Buszewski, Sens. Actuat. B Chem. 202, 615 (2014).

[6] B. Henderson, A. Khodabakhsh, M. Metsälä et al., Appl. Phys. B 124, 161 (2018).

[7] L.S. Rothman, I.E. Gordon, Y. Babikov et al., J. Quantitat. Spectrosc. Radiat. Transf. 130, 4 (2013).

[8] S. Lundqvist, P. Kluczynski, R. Weih, M. von Edlinger, L. Nähle, M. Fischer, A. Bauer, S. Hofling, J. Koeth, Appl. Opt. 51, 6009 (2012).

[9] D. Rehle, D. Leleux, M. Erdelyi, F. Tittel, M. Fraser, S. Friedfeld, Appl. Phys. B 72, 947 (2001).

[10] G. Peach, Adv. Phys. 30, 367 (1981).

[11] J.J. Harrison, N.D. Allen, P.F. Bernath, J. Quantitat. Spectrosc. Radiat. Transf. 111, 357 (2010).

[12] A. O'Keefe, D. Deacon, Rev. Sci. Instrum. 59, 2544 (1988).

[13] J.H. Van Helden, R. Peverall, G.A.D. Ritchie, G. Berden, R. Engeln, Cavity Enhanced Techniques Using Continuous Wave Lasers, Wiley-Blackwell, 2009.

[14] T. Stacewicz, J. Wojtas, Z. Bielecki, M. Nowakowski, J. Mikołajczyk, R. Mędrzycki, B. Rutecka, Opto-Electron. Rev. 20, 53 (2012).

[15] T. Stacewicz, Z. Bielecki, J. Wojtas, P. Magryta, J. Mikolajczyk, D. Szabra, OptoElectron. Rev. 24, 82 (2016).

[16] J. Mikołajczyk, J. Wojtas, Z. Bielecki, T. Stacewicz, D. Szabra, P. Magryta, A. Tkacz, M. Panek, Metrol. Meas. Syst. 23, 481 (2016).

[17] M. Winkowski, T. Stacewicz, Opt. Commun. 480, 126464 (2020).

[18] J.R. Braswell, D.R. Spiner, R.K. Hoffman, Appl. Microbiol. 20, 765 (1970).

[29] M. Karlsson, "Characterization of Absorption Spectra of Molecular Constituents in the Mid-Infrared Region and Their Role as Potential Markers for Breath Analysis".

[20] D.W. Allan, Proc. IEEE 54, 221 (1966). 